TITLE:

\title{
Effect of preozonation on wastewater reclamation by the combination of ozonation and soil aquifer treatment
}

\section{$\operatorname{AUTHOR}(S):$}

Echigo, S.; Nakatsuji, M.; Takabe, Y.; Itoh, S.

\section{CITATION:}

Echigo, S.... [et al]. Effect of preozonation on wastewater reclamation by the combination of ozonation and soil aquifer treatment. Water Science \& Technology: Water Supply 2015, 15(1): 101-106

\section{ISSUE DATE:}

2015-02

URL:

http://hdl.handle.net/2433/200271

\section{RIGHT:}

(CIWA Publishing 2015. The definitive peer-reviewed and edited version of this article is published in Water Science\& Technology: Water Supply Vol 15 No 1 pp 101-106 doi:10.2166/ws.2014.089 and is available at www.iwapublishing.com; The full-text file will be made open to the public on 1 March 2016 in accordance with publisher's 'Terms and Conditions for Self-Archiving'.; この論文は出版社版でありません。引用の際には出版社版をご確認ご利用ください。; This is not the published version. Please cite only the published version. 


\title{
Effect of Preozonation on the Wastewater Reclamation by the Combination of Ozonation and Soil Aquifer Treatment
}

\author{
S. Echigo*, M. Nakatsuji**, Y., Takabe*, S. Itoh* \\ * Department of Environmental Engineering, Graduate School of Engineering, Kyoto University, Nishikyo, \\ Kyoto 615-8540, Japan (E-mail: echigo@urban.env.kyoto-u.ac.jp) \\ ** Graduate School of Global Environmental Studies, Kyoto University, Nishikyo, Kyoto 615-8540, Japan
}

\begin{abstract}
A series of column experiments and risk evaluation revealed that preozonation was found to be a better option to enhance the performance of soil aquifer treatment (SAT) than ozonation after SAT for controlling a wide range of dissolved organic carbon (DOC), trace organic contaminants and disinfection byproducts. Our results are a good example to show that upgrading pretreatments can be more effective than adding extra treatments after SAT, and it is important to optimize a water reclamation system as a whole system.
\end{abstract}

\section{Keywords}

Soil aquifer treatment; ozonation; trace organic compounds; disinfection byproducts

\section{INTRODUCTION}

Many parts of the world are facing serious water shortage because of the uneven distribution of water resources and the concentration of the population in large cities. Also, extreme weather conditions caused by global climate change may further complicate the situation (e.g., Arnell, 1999). Water reclamation has become an important option to make up for the limited access to water sources. In extremely dry areas of the world, wastewater reclamation has been employed even for direct potable use in the past several decades (e.g., Asano et al., 2007).

Soil aquifer treatment (SAT) is a common way for water reclamation. This technique is different from other engineered treatment technologies (e.g., reverse osmosis (RO)) for its use of natural environment (Dillon et al., 2010). SAT, however, is not a popular option in highly populated areas because of the limitation in land space (i.e., short HRT) and the complex geological structure in the subsurface environment. Under this situation, it is ideal to fully utilize the advantage of SAT as a part of water reclamation systems along with wastewater treatment and drinking water treatment. That is, an effective combination of SAT and other treatment processes should be sought to design reclamation systems to overcome the limitations of SAT in urban areas.

Ozonation and other oxidation technologies are promising options to improve the performance of water reclamation systems with SAT in various ways. Preoxidation treatment is expected to enhance the biodegradability of organic compounds. Hübner et al. (2012) found that the combination of ozonation and artificial groundwater recharge of a lake water receiving wastewater effluent was better than artificial groundwater recharge alone for DOC reduction. Also, postoxidation could be more effective for the oxidation of trace organic compounds because it is performed under a lower DOC concentration than preoxidaiton (i.e., with a higher availability of oxidants). However, to the best of our knowledge, no systematic comparison between these two processes (i.e., preoxidation + SAT and SAT + postoxidation) has been made. In this study, to maximize the potential of SAT, we evaluated the effect of preozonation on the removal of organic compounds (i.e., DOC and other trace organic compounds including major disinfection byproducts). Also, postozonation experiments were performed for comparison. 


\section{Reagents}

All the chemicals used in this study were purchased from Wako (Japan), and of special grade or the highest grade available unless otherwise noted. They were used without further purification. For chlorination, sodium hypochlorite (Chemical grade, Wako) was used. For the analysis of pharmaceutical and personal care products (PPCPs) with an LC-MS/MS system, formic acid and acetonitrile (LC/MS grade, Wako) were used for the preparation of mobile phase. Carbamazepine (CBZ, biochemical grade, Wako), clarithromycin (CAM, biochemical grade, Wako), sulpiride (SLP, biochemical grade, Wako), DEET (>98\%, TCI (Japan)), and crotamiton (CRT, >97\%, SigmaAldrich (USA)) were purchased as the standard compounds of PPCPs. All the aqueous solutions were prepared with ultra pure water produced with a Millipore Academic-A10 system.

\section{Feed water}

An effluent from an actual wastewater treatment with anaerobic-anoxic-aerobic process $\left(\mathrm{A}_{2} \mathrm{O}\right)$ in Kyoto City (Japan) was used as the feed water for this study. This effluent was filtered with a cellulose membrane (5A, Advantec (Japan)) and store in a refrigerator before use.

\section{Experimental matrix and target indices}

Treatment performances under seven different conditions were compared in this study (Figure 1): ozonation alone, SAT alone, and the combination of ozonation and SAT with different orders and ozone doses (5 or $10 \mathrm{mg} / \mathrm{L}$ ). DOC and chlorine demand were monitored as the general water quality indices. EDTA and 1,4-dioxane, and the five PPCPs mentioned above were measured as the representative trace organic compounds. In addition, bromate ion concentration and the formation potentials of four major trihalomethanes (THMs) and nine major haloacetic acids (HAAs) were evaluated as the major disinfection byproducts (DBPs). Ozonation conditions are denoted as “O3(5)” for ozonation at an ozone dose of $5 \mathrm{mg} / \mathrm{L}$, and “O3(10)” for $10 \mathrm{mg} / \mathrm{L}$.

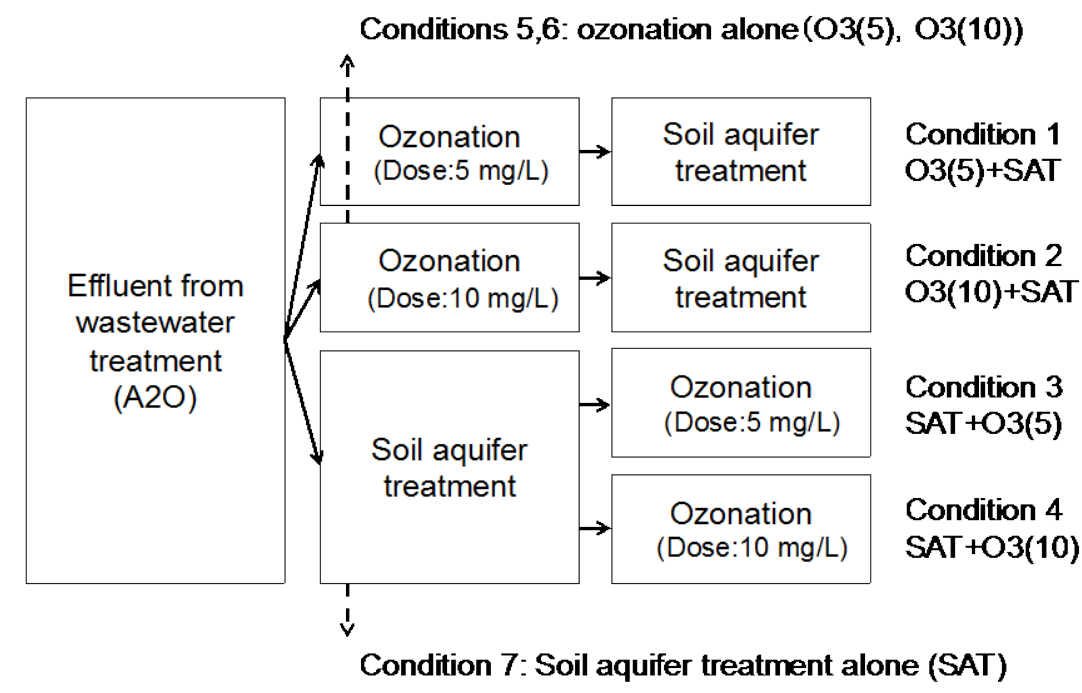

Figure 1. Experimental Matrix.

\section{Soil aquifer treatment (SAT)}

Three laboratory-scale sand columns were operated under an aerobic condition. The columns (150 $\mathrm{cm}$ height, $15 \mathrm{~cm}$ i.d.) consisted of the bottom layer (10 cm of gravel layer) and the sand layer (110 $\mathrm{cm})$. The sand was collected in the Shiga area, Japan, and used without sieving. The water head was maintained at $20 \mathrm{~cm}$ below the top of the sand layer (i.e., the top $20 \mathrm{~cm}$ was operated under unsaturated conditions). The columns were fed with different test solutions at a flow rate of 0.8 mL/min: $\mathrm{A}_{2} \mathrm{O}$ water or ozonated $\mathrm{A}_{2} \mathrm{O}$ water. The HRT and temperature were controlled at 
approximately 7 days and $20{ }^{\circ} \mathrm{C}$, respectively. The three columns were operated for two to three months for acclimatization before routine monitoring of effluent quality was started in the first week of August 2012.

\section{Preozonation and postozonation}

Ozonation was performed in semibatch mode. Ozone gas produced from ultrapure oxygen by an ozone generator (AZH-3S, Hamamatsu Vegetable(Japan)) was continuously fed to the $\mathrm{A}_{2} \mathrm{O}$ water in the glass ozone contactor (volume, $3.3 \mathrm{~L}$ ) through a bubble diffuser at the bottom.

\section{Analytical methods}

DOC was determined with a TOC analyzer (TOC-L, Shimadzu(Japan)) in nonpurgeable-organiccarbon (NPOC) mode. Chlorine demand was determined based on the chlorine consumption in 24 hours. EDTA was measured by an HPLC method after derivatization (Kemmei et al., 2007). 1,4dioxane concentration was measured by GC/MS after solid-phase extraction (Nishimura et al., 2010). PPCPs were measured by LC-MS/MS after solid-phase extraction (Yonetani et al., 2012). Bromate ion concentration was determined by an ion-chromatography with a postcolumnderivatization method (JWWA, 2011). For the formation potentials of THMs and HAAs, samples were chlorinated for 24 hours. HAA concentrations were determined by GC/MS after derivatization to the corresponding methyl esters (USEPA, 2003). THM concentrations were measured by GC/MS analysis using the same column as in HAA analysis following liquid-liquid extraction with pentane (APHA et al., 2005).

\section{RESULTS AND DISCUSSION}

\section{DOC profiles}

The DOC profiles after acclimatization are shown Figure 2. As expected, preozonation itself did not change DOC. When preozoantion was applied, however, regardless the ozone dose, the DOC levels after SAT were lower than that of SAT alone (average DOC removals: $80.4 \%$ for O3(5)+SAT, $82.4 \%$ for O3(10), and $74.3 \%$ for SAT alone). This was probably because the biodegradability of dissolved organic matter (DOM) in the $\mathrm{A}_{2} \mathrm{O}$ water was enhanced by ozonation (Treguer, et al., 2010; Sallanko, J. and Välsänen, T, 2013). Postozonation decreased DOC levels to some extent, but was less effective than the combination of preozonation and SAT. Relatively high ozone doses to low DOC levels appeared to result in partial mineralization of DOM through radical reactions (i.e., self-decomposition of ozone) (e.g., von Gunten, 2003).

\section{Chlorine demand}

SAT alone reduced chlorine demand by $85.9 \%$, and was much more effective than ozonation alone for the reduction of chlorine demand. Postozonation did not decrease chlorine demand. On the other hand, the combination of preozonation and SAT achieved slightly lower chlorine demand (approximately 90\% reduction for both ozone doses) than SAT alone.

The above results on DOC and chlorine demand suggest that the combination of preozonation and SAT be effective for the removal organic compounds and the reduction of the reactivity of DOM to oxidizing and halogenating reagents in general. However, for recalcitrant compounds (e.g., 1,4dioxane), the combination of SAT and postozonation may be better as a lower DOC during ozonation would enhance the availability of hydroxyl radicals to target compounds. This point will be further discussed in the next subsection. 


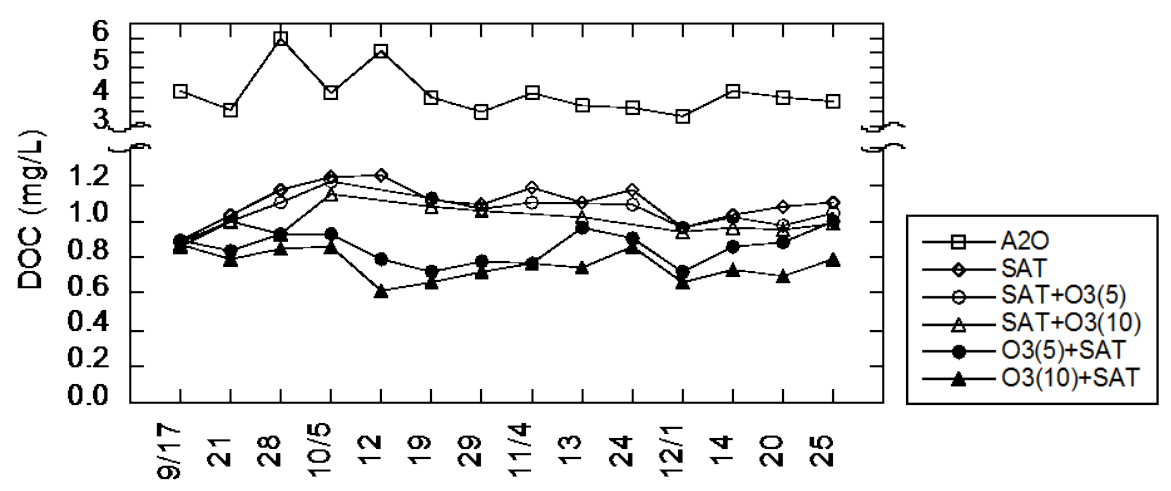

Figure 2. Comparison of Time-DOC profiles after acclimatization.

\section{Trace organic compounds}

The combination of SAT and postozonation was the most effective option for the removal of 1,4dioxane among the options tested contrary to the results on DOC (Figure 3). The removal was very limited when SAT alone was applied. Also, no clear difference was observed between ozonation and the combination of preozonation and SAT. Thus, 1,4-dioxane was mainly removed during ozonation, and the efficiency of ozonation was improved by higher availability of hydroxyl radicals with the reduced background DOC level after SAT.

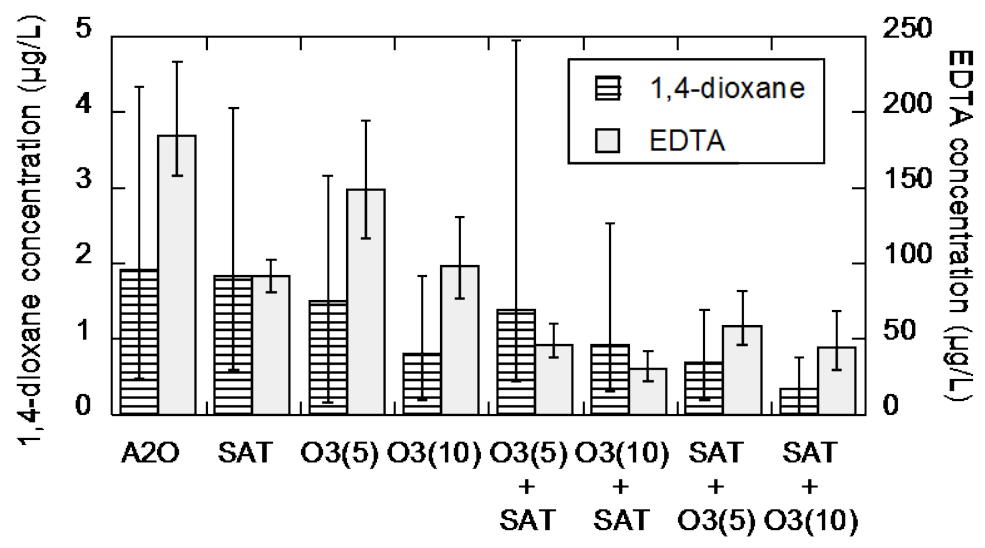

Figure 3. Comparison of 1,4-dioxane $(n=8)$ and EDTA $(n=7)$ removals.

For EDTA, the combination of preozonation and SAT was better than other treatment conditions. Similarly to the DOC profiles, the enhanced biodegradability of DOM by preozonation improved the removal under this condition.

PPCPs were almost completely removed during ozonation regardless the order of treatment. Thus, it can be said that ozonation is a good way to backup SAT for controlling this class of chemicals. However, one should keep in mind that ozonation does not completely mineralize these compounds. The health effects and fate of these transformation products need to be addressed in the future research. It is also of note that CBZ concentration increased after SAT. This could be due to deconjugation reactions (Vieno et al., 2007).

\section{Disinfection byproducts}

Bromate ion was below the detection limit $(<0.5 \mu \mathrm{g} / \mathrm{L})$ for SAT, O3(5), O3(5)+SAT (Figure 4). Ozone appeared to be consumed rapidly by the reaction with DOM under these conditions. Bromate 
ion was detected under other conditions. In particular, higher bromate ion concentrations than the WHO guideline value (10 $\mu \mathrm{g} / \mathrm{L})$ were found for the SAT + O3(10) condition. Obviously, this is due to higher availability of molecular ozone and hydroxyl radicals for oxidation of bromide ion. It should be noted that bromate ion would be a major constraint when applying postozonation to remove trace organic compounds resistant to biological treatment.

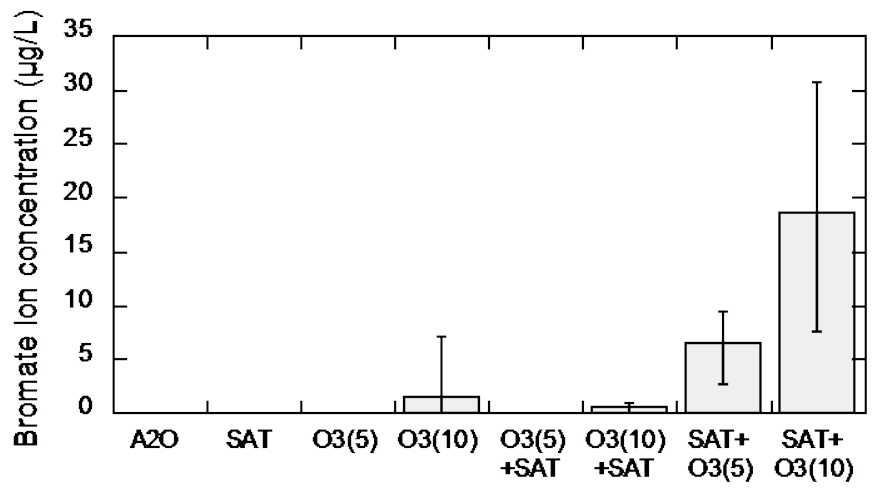

Figure 4. Comparison of bromate ion concentration $(n=8)$.

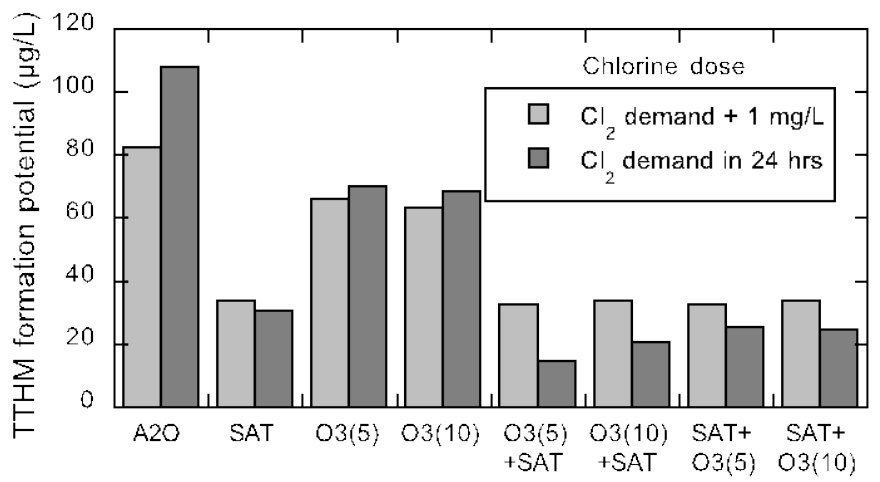

Figure 5. Comparison of THMFPs ( $\mathrm{n}=6$ for chlorine dose $=$ chlorine demand for $24 \mathrm{hrs}$, and $\mathrm{n}=2$ for chlorine dose $=$ chlorine demand for $24 \mathrm{hrs}+1 \mathrm{mg} / \mathrm{L}$ ).

Similar THMFPs were observed for SAT alone, preozonation + SAT, and SAT + postozonation. The combination of preozonation + SAT with the lower chlorine dose (= chlorine demand for 24 hours) was slightly better for the reduction of THMFPs than the postozonation option (Figure 5). The bromine incorporation ratio was higher for the preozonation option. These results may reflect the fact that DOM after the treatment by preozonation + SAT is less reactive to chlorine than DOMs in other conditions. A similar trend was found for HAAFPs (data not shown).

\section{Risk evaluation}

Based on the results obtained in this study, we attempted to compare the total risks for the options tested. For this purpose, the results (the maximum concentrations for the target compounds or indices, hereinafter denoted as $C$ ) were classified into three categories: the safe zone, for $C$ lower than $10 \%$ of the standards or guideline values (STD); the monitoring zone, those for $10 \%$ of STD $\leq$ $C \leq \mathrm{STD}$; danger zone, those above STD. Then, for data points in the safe zone and the monitoring zone, 0 point and C/STD point were assigned, respectively. A treatment option with items in danger zone was excluded from the evaluation. Table 1 summarizes the result of the evaluation. In total, the combination of preozonation and SAT at an ozone dose of $5 \mathrm{mg} / \mathrm{L}$ was the best option among those tested in this study. One may argue that lower risks were obtained for the preozonation options because of high concentration of bromate ion resulting from high ozone doses as drinking 
water treatment, and the postozonation options could be better if the ozone dose was optimized. However, our evaluation excluding bromate ion also indicated that preozonation options are better than postozonation options. Thus, even with the optimized ozone dose, preozonation would be a more appropriate treatment option.

The above results imply the importance of upgrading a water reclamation system as a total system. That is, upgrading pretreatment may be more effective than upgrading the following drinking water treatment process. Also, it should be emphasized that relatively high ozone doses were used in this study, and only the combination of ozonation and SAT was discussed. For more detailed and realistic optimization including cost, considerations on lower ozone dose and other treatment steps (e.g., coagulation and activated carbon treatment) would be necessary.

Table 1. Summary of risk evaluation (Values shown in the table are C/STD. The standard value for HAA5 is the one regulated by USEPA (2006). Other standard and guideline values are those in Japan. The evaluation on 1,4-dioxane and PPCPs are not listed as all the evaluations were in the safe zone.)

\begin{tabular}{|c|c|c|c|c|c|c|c|c|}
\hline & A2O & SAT & $\mathrm{O} 3(5)$ & $\mathrm{O} 3(10)$ & O3(5)+SAT & O3(10)+SAT & $\mathrm{SAT}+\mathrm{O} 3(5)$ & $\mathrm{SAT}+\mathrm{O} 3(10)$ \\
\hline TCM & $>$ STD & 0.22 & 0.53 & 0.61 & 0.20 & 0.21 & 0.24 & 0.24 \\
\hline BDCM & 0.61 & 0.39 & $>S T D$ & 0.97 & 0.41 & 0.45 & 0.36 & 0.45 \\
\hline DBCM & 0.00 & 0.10 & 0.15 & 0.16 & 0.00 & 0.00 & 0.00 & 0.00 \\
\hline ТВМ & 0.00 & 0.00 & 0.00 & 0.00 & 0.00 & 0.00 & 0.00 & 0.00 \\
\hline T-THMs & 0.89 & 0.36 & 0.83 & 0.72 & 0.35 & 0.38 & 0.33 & 0.37 \\
\hline DCA & 0.93 & 0.26 & 0.59 & 0.69 & 0.19 & 0.20 & 0.27 & 0.25 \\
\hline TCA & 0.23 & 0.00 & 0.14 & 0.13 & 0.00 & 0.00 & 0.00 & 0.00 \\
\hline HAA5 & $>$ STD & 0.34 & 0.90 & 0.95 & 0.31 & 0.27 & 0.32 & 0.30 \\
\hline EDTA & 0.47 & 0.21 & 0.39 & 0.26 & 0.12 & 0.00 & 0.16 & 0.14 \\
\hline $\mathrm{BrO}_{3}^{-}$ & 0.00 & 0.00 & 0.00 & 0.71 & 0.00 & 0.11 & 0.95 & $>$ STD \\
\hline Total & $>$ STD & 1.88 & $>$ STD & 5.20 & 1.58 & 1.62 & 2.63 & $>$ STD \\
\hline
\end{tabular}

\section{CONCLUSIONS}

The combination of preozonation and SAT was compared with the combination of SAT andpostozonation for controlling DOC, chlorine demand, PPCPs, and disinfection byproduts for water reclamation. Better reductions of DOC and EDTA were observed with the preozonation option. On the other hand, for the removal of 1,4-dioxane, the postozonation option was better. The PPCPs monitored were almost completely oxidized in both preozonation and postozonation. The comparison of total risks for the options tested indicated that the combination of preozonation and SAT was the best option for the target compounds and indices monitored in this study.

\section{ACCKNOWLEDGEMENTS}

This study was supported by JST, CREST. We also appreciate Kyoto City Waterworks Bureau for providing the feed water and technical supports for this project.

\section{REFERENCES}

Arnell, N.W. 1999 Climate change and global water resources. Global Environ. Change. 9, S31-S49.

APHA, AWWA \&WEF 1998 Standard Methods for the Examination of Water and Wastewater, 21st edition. American Public Health Association/American Water Works Association/Water Environment Federation, Washington, DC.

Asano, T., Burton, F.L., Leverenz, H.L., Tsuchihashi, R., and Tchobanoglous, G. 2007 Water Reuse. Metcalf \& Eddy, New York. 
Dillon, P., Toze, S., Page, D., Vanderzalm, J., Bekele, E., Sidhu, J. \& Rinck-Pfeiffer, S. 2010 Managed aquifer recharge: rediscovering nature as a leading edge technology. Water Sci. Technol. 62, 2338-2345.

Hübner, U., Miehe, U. \& Jekel, M. 2012 Optimized removal of dissolved organic carbon and trace organic contaminants during ozonation and artificial ground water recharge. Water Res. 46, 6059-6068.

JWWA 2011 Standard Methods for the Examination of Water. Japan Waterworks Association, Tokyo.

Kemmei, T., Kodama, S., Yamamoto, A., Inoue, Y. \& Hayakawa, K.2007 Determination of sequestering agents in cosmetics and synthetic detergents by high-performance liquid chromatography with ultraviolet detection. J. Chromatogr. A 1171(1-2), 63-68.

Nishimura, F., Okuda, K., Hasegawa, E. \& Tsuno, H. 2010 Removal of 1,4-dioxane from landfill leachate by $\mathrm{O}_{3}$ and $\mathrm{O}_{3} / \mathrm{H}_{2} \mathrm{O}_{2}$ process. Environ. Eng. Res. 47, 497-505.

Sallanko, J. \& Väisänen, T. 2013 Effects of ozonation on AOC content of humic Finnish groundwater. Ozone: Sci. Eng. 35 (2), $86-$ 89.

Treguer, R., Tatin, R., Couvert, A., Wolbert, D. \& Tazi-Pain, A. 2010 Ozonation effect on natural organic matter adsorption and biodegradation - Application to a membrane bioreactor containing activated carbon for drinking water production. Water Res. 44 (3), 781-788.

USEPA 2003 Method 552.3: Determination of haloacetic acids and dalapon in drinking water by liquid-liquid microextraction, derivatization, and gas chromatography with electron capture detection.

USEPA 2006 National primary drinking water regulations: Stage2 disinfectants and disinfection byproduts rule; Final Rule. Fed. Regist. 71(2), 388-493.

Vieno, N., Tuhkanen, T. \& Kronberg, L. 2007 Elimination of pharmaceuticals in sewage treatment plants in Finland. Water Res. 41 (5), 1001-1012.

von Gunten, U. 2003 Ozonation of drinking water: Part I. Oxidation kinetics and product formation. Water Res. 37 (7), $1443-1467$.

Yonetani, T., Phattarapattamawong, S., Echigo, S., Morita, Y., Ohkouchi, Y. \& Itoh, S. 2012 Fate of pharmaceutical and personal care products in treated sewage. J. JSCE, Ser. G 68(7), III_419-III_428. 